capacity to deliver health information to patients via mobile telephones.

The WHO snapshot of Canada is "worrisome," says Postl. "It's been very slow progress and remains pretty incomplete."

Among the alarming indicators in WHO's profile of Canada, Postl says, are a set of barriers to elearning within medical education at a time when "we've got a gap between the expectations and growing skill sets of our students who now live and breathe in the electronic world by second nature, and our educational systems that are kind of catching up. ... The students know they can't provide effective and safe care with the paper and pencil system where charts disappear."

The WHO profile indicates the time has come for a much more detailed and comprehensive review of Canada's ehealth status, he adds.

Canadians are often "stunned" to discover that basic health information technologies are unavailable, Postl argues. "I think the public thinks that much more exists than actually does exist."

"Do we know what is happening? The answer is no," says Barré. "A current state assessment would be very helpful."

Infoway has struggled to meet such goals as a commitment to ensure that health professionals have access to health records for $50 \%$ of Canadians by 2010 . Kirk Fergusson, Infoway's vice president, corporate affairs, told CMAJ in January that the goal has been achieved for $49.3 \%$ of Canadians. But he did not respond to a request for a data breakout to elucidate how that figure was derived.

Tamblyn argues that Canada also needs to develop an ambitious new basket of national policies to galvanize ehealth progress. The policies should facilitate timely clinical informationsharing between providers in all settings, make personal health records and self-management tools accessible, enable reimbursement for evisits, enable interdisciplinary teamwork and provider consultation, establish incentives for using electronic reminders for preventive care and personalized health care, and implement patient outcomebased financial incentives, she says.

Canada Health Infoway declined to comment on the WHO atlas and referred questions to Health Canada.

David Thomas, spokesman for Health Canada, says "the timing of the WHO survey in 2009 coincided with advance planning for H1N1, a public health priority in Canada, so unfortunately not all of the provinces and territories were able to provide input to the survey. In addition, as with any survey, there are limitations, which include the interpretation and applicability of the questions."

Thomas also notes that "ehealth applications were difficult to assess, and the responses provided may not apply equally across the country." - Paul Christopher Webster, Toronto, Ont.

CMAJ 2011. DOI:10.1503/cmaj.109-3783

\title{
The centralized approach to guidelines development
}

$\mathrm{T}$ he landscape of clinical practice guidelines development in Canada might best be described as fragmented. There is no central source that funds or coordinates guidelines development across the country. Guideline writers can attempt to secure funding from the government, though their chances of success are slim, so instead they turn to private donors or, in most cases, to disease-specific medical societies, many of which pay the bills with money from pharmaceutical companies or medical device manufacturers.

Though some other countries have a similar scattershot approach to medical knowledge translation, there are a few that consider clinical guidelines a national priority, or at least worthy of a central coordinating body. In the United Kingdom, for example, the National Institute for Clinical Evidence (NICE), established in 1999 to provide clinical guidance to the National Health Service, has a clinical guideline program that is "one of the largest, most productive and best organized developers of clinical guidelines in the world," according to the World Health Organization (www.euro.who.int/_data/assets /pdf_file/0003/96447/E89740.pdf).

Some Canadian experts in medical knowledge translation wonder if Canada should also adopt a centralized approach to guidelines development.

"Aside from the Canadian Task Force on Preventive Health Care, there is little public funding for guideline development in Canada. Many guideline panels have relied on industry (and continue to do so). This is problematic because it creates an obvious potential for conflict of interest," Dr. Gordon Guyatt, professor of clinical epidemiology and biostatistics at McMaster University in Hamilton, Ontario, writes in an email.

"Whether Canada should have a NICE equivalent that itself produces guidelines, I'm not sure," writes Guyatt, a leading proponent of evidencebased approaches to clinical care. "This may be the best approach, but an alternative would be a funding/oversight body that would support groups that wish to do guidelines."

Until the day a central body is estab- lished, if that day ever arrives, researchers who want to fill in gaps in clinical knowledge will be on their own. Anna Taddio, associate professor of pharmacy at the University of Toronto in Ontario, knows that all too well, having recently led the development of a set of guidelines for reducing the pain of childhood vaccination (www.cmaj.ca /cgi/doi/10.1503/cmaj.101720).

Most guideline writers, except those backed by a well-funded specialty society, must cobble together scraps of funding from various sources - asking for $\$ 5000$ here, $\$ 5000$ there. Taddio was able to secure some money from the Canadian Institutes of Health Research (CIHR). For the knowledge translation part of her guidelines, she sought dissemination monies from the Public Health Agency of Canada. No luck.

"We were told that's not covered as a grantable item," says Taddio. "We used only CIHR money and free time."

In the United States, as in Canada, guidelines come from numerous organizations. According to the Guidelines International Network, about $80 \%$ of 
US guidelines are written by medical specialty societies, professional organizations and disease-specific societies. The US government has funded several guidelines, most of them produced by the Centers for Disease Control and some branches of the National Institutes of Health.

As noted on the Guidelines International Network's website, having guidelines written by multiple sources allows many individuals to gain experience in guideline development, but it can also lead to problems, especially when groups produce competing guidelines (www.g-i-n.net/newsletter /country-updates/country-update-usa). "However, the multiplicity of developers has created a system that can be fragmented and result in variable levels of methodological rigor and conflicting guidance for physicians and other health-care professionals. Due to the disjointed efforts and lack of a centralized funding source, incentives do not always properly align to promote harmonization of competing guidelines."

Similarly, Australian clinical guidelines are written by a range of organizations, including various government agencies and professional organizations. One study identified 34 clinical guidelines from 32 organizations (Med $J$ Aust 1996; 165: 574-6). The lack of a central body to implement publishing standards may explain the almost com- plete lack of methodological transparency within those 34 guidelines. For instance, 29 of them failed to describe the methodology used to identify evidence and none fully described how the identified evidence was synthesized.

Another study found that the number of clinical guidelines published in Australia has grown rapidly, tripling in the past 15 years (MJA 2010; 192:490-4). Though government agencies funded or produced almost half of them, the guideline landscape remains fractured, because "most health departments had no central point of reference for guidelines and were unable to provide comprehensive information about the guidelines they produced, commissioned or helped fund."

Transparency also appears to be slowly increasing within Australian guidelines. About one-third of the 313 guidelines identified provided details about their search methodology. But there was little reporting of the competing interests of guideline developers. Another problem, according to the study, is that the lack of a coordinated national approach has resulted in a "sporadic oneoff" approach to guideline development, meaning that guidelines are not adequately reassessed and updated.

"A coordinated national approach to funding, producing and updating highquality guidelines in priority health areas may provide opportunities to gain greater returns on the current invest-

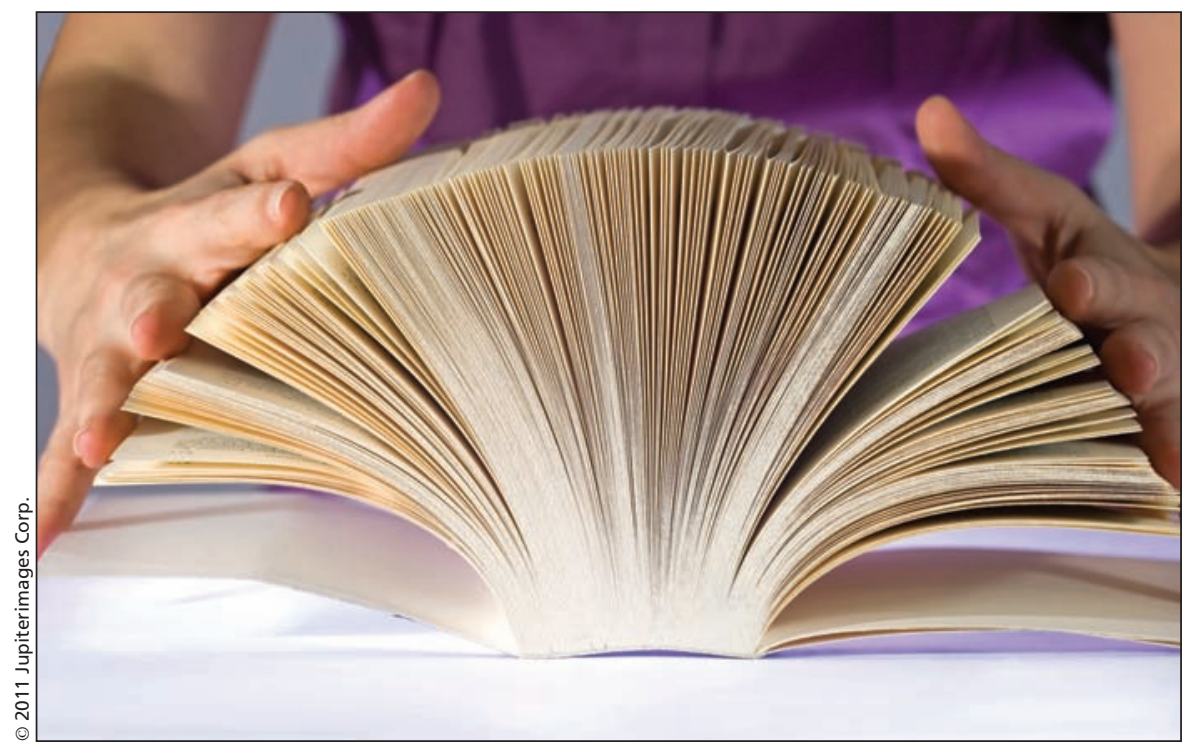

"Knowledge translation in general is important. There is so much literature out there. Somebody needs to synthesize it. Nobody can understand it all," says Anna Taddio, associate professor of pharmacy at the University of Toronto in Ontario. ment in clinical practice guidelines," the paper concludes.

Several countries have been successful in establishing coordinated national approaches to guideline development. In 1997, the Netherlands created a national network, the EBRO platform, to facilitate collaboration in the production of evidence-based guidelines. In Singapore, the Ministry of Health's department of clinical standards has taken the lead, while most guidelines in New Zealand are funded or created by two central government agencies: the Ministry of Health and the Accident Compensation Corporation.

The primary advantage of having a large government agency in charge of clinical guidelines is that it has access to a wide range of resources, unlike an individual researcher in Canada who must scramble for funding to produce a set of guidelines. These resources enable sustained productivity. For instance, the UK's NICE has published 120 guidelines and 60 more are in the works, on a wide range of topics including autism, colorectal cancer, epilepsy, osteoporosis, and schizophrenia.

Of course, there are also disadvantages. First, there are the inevitable delays, and ensuing frustrations, that come with dealing with a large bureaucracy. Also, government bodies tend to be rigid in their approach to developing anything, be it a policy, law or clinical guidelines, when a more flexible approach could yield greater results. "The current approach to the development of guidelines is both expensive and slow," the WHO report states. "Alternative types of guidelines should also be considered, such as shorter, more focused guidelines, umbrella guidelines, rapid response guidelines and adapted guidelines from other institutions."

However they are funded or coordinated in Canada, clinical practice guidelines are vital to improving patient care and deserve more attention than they currently receive, says Taddio. "Knowledge translation in general is important. There is so much literature out there. Somebody needs to synthesize it. Nobody can understand it all." — Roger Collier, CMAJ

CMAJ 2011. DOI:10.1503/cmaj.109-3784 